\title{
Failure of dihydroartemisinin plus piperaquine treatment of falciparum malaria by under-dosing in an overweight patient
}

Jean Baptiste Roseau ${ }^{1,2}$, Bruno Pradines ${ }^{3,45^{*}}$, Nicolas Paleiron ${ }^{2,6}$, Serge Vedy ${ }^{2}$, Marylin Madamet ${ }^{4,5,7}$, Fabrice Simon ${ }^{8,9}$ and Emilie Javelle ${ }^{8^{*}}$

\begin{abstract}
Background: Artemisinin-based combination therapy (ACT) introduced in the mid-1990s has been recommended since 2005 by the World Health Organization as first-line treatment against Plasmodium falciparum in all endemic countries. In 2010, the combination dihydroartemisinin-piperaquine (DP) was recommended for the treatment of uncomplicated $P$. falciparum malaria. DP is one of the first-line treatments used by the French army since 2013.

Case presentation: A case of P. falciparum clinical failure with DP at day 20 was described in a $104 \mathrm{~kg}$ French soldier deployed in Djibouti. He was admitted to hospital for supervision of oral treatment with DP [ $40 \mathrm{mg}$ dihydroartemisinin (DHA) plus $320 \mathrm{mg}$ piperaquine tetraphosphate (PPQ)]. This corresponded to a cumulative dose of $4.6 \mathrm{mg} / \mathrm{kg}$ $\mathrm{DHA}$ and $37 \mathrm{mg} / \mathrm{kg} \mathrm{PPQ}$ in the present patient, which is far below the WHO recommended ranges. No mutation was found in the propeller domain of the Kelch 13 (k13) gene, which is associated with artemisinin resistance in Southeast Asia. Pfmdr1 N86, 184F, S1034 and N1042 polymorphisms and haplotype 72-76 CVIET for the pfcrt gene were found in the present case. There was no evidence of resistance to DP.

Conclusion: This case confirms the risk of therapeutic failure with dihydroartemisinin-piperaquine by under-dosing in patients weighing more than $100 \mathrm{~kg}$. This therapeutic failure with DP by under-dosing highlighted the importance of appropriate dosing guidelines and the need of research data (efficacy, pharmacokinetics and pharmacodynamics) in over-weight patient group.
\end{abstract}

Keywords: Malaria, Plasmodium falciparum, Anti-malarial, In vitro, Resistance, Clinical failure, Under-dosing, Djibouti, Dihydroartemisinin, Piperaquine

\section{Background}

Artemisinin-based combination therapy (ACT) introduced in the mid-1990s has been recommended since 2005 by the World Health Organization (WHO) as first-line treatment against Plasmodium falciparum in all endemic countries.

\footnotetext{
*Correspondence: bruno.pradines@gmail.com; emilie.javelle@gmail.com ${ }^{3}$ Unité de Parasitologie et d'Entomologie, Département des Maladies Infectieuses, Institut de Recherche Biomédicale des Armées, Marseille, France

${ }^{8}$ Service de pathologie infectieuse et tropicale, Hôpital d'Instruction des Armées Laveran, Marseille, France

Full list of author information is available at the end of the article
}

Combined with wide-spread use of insecticide-treated bed nets, ACT has led to a significant reduction in malaria incidence and mortality, especially in sub-Saharan Africa [1]. However, with 214 million cases globally leading to an estimated 438,000 deaths worldwide in 2015, malaria remains a public health concern [2]; moreover, ACT therapeutic failures are increasing in Cambodia, where resistance to previous first-line anti-malarial drugs also first emerged [3]. Today, artemisinin resistance has been documented in Southeast Asia and must be closely monitored [4].

Clinical resistance, defined by a slow parasite clearance [3], is in vitro correlated with an increase in the 
ring-stage survival rate after contact with artemisinin [5]. Recently, mutations in the propeller domain of the Kelch 13 (k13) gene (PF3D71343700), especially the $\mathrm{Y} 493 \mathrm{H}$, R539T, I543T, and C580Y mutations, have been associated with in vivo and in vitro resistance to artemisinin in Southeast Asia P. falciparum strains [6-8]. Currently, these mutations have not been identified in African $P$. falciparum isolates [9-15]. K13 mutations as well as patients with slow clearing parasites were found in and some African countries (Kenya, Democratic Republic of Congo and Nigeria) [4]. However, there was no confirmation about spreading artemisinin resistance to Africa.

Nevertheless, addressing ACT-failure requires a systematic approach, and the conclusion of drug resistance is based on a body of clinical and scientific arguments. Poor compliance (insufficient oversight or intolerance) and under-dosing (insufficient dosage, poor absorption, drug interactions or defects in drug metabolism) may also contribute.

In this report, a failure of dihydroartemisinin-piperaquine (DP) anti-malarial treatment was identified in a patient weighing $104 \mathrm{~kg}$.

\section{Case presentation}

A 35-year-old French soldier was deployed to Djibouti. He had no medical history, no recent trips except a return to France during summer holidays and intermittent observance of doxycycline (100 mg/day) malaria prophylaxis. He presented with fever, headaches, and diarrhoea for 4 days with paracetamol self-medication. His weight was $104 \mathrm{~kg}$. His blood pressure was $143 / 78 \mathrm{mmHg}$, and his pulse rate was $84 \mathrm{bpm}$. A rapid diagnostic test (RDT) for malaria was positive for P. falciparum (Core Malaria ${ }^{\mathrm{TM}}$ $\mathrm{pan} / \mathrm{pv} / \mathrm{pf}$, Fumouze diagnostics). Therefore, he was referred to a military hospital. Laboratory tests revealed a few abnormalities: lymphopenia $\left(0.6 \times 10^{9} / 1\right.$ lymphocyte count) and thrombocytopenia $\left(30 \times 10^{9} / 1\right.$ platelet count $)$ without anaemia and moderate elevation in hepatic enzymes (ASAT $125 \mathrm{UI} / \mathrm{l}$ and ALAT $147 \mathrm{UI} / \mathrm{l}$ ) and in bilirubin $(30 \mu \mathrm{mol} / \mathrm{l})$. Parasite detection in blood using quantitative buffy coat (QBC) was positive, and examination of thin blood smear stained by the May-GrünwaldGiemsa method confirmed the diagnosis of $P$. falciparum infection with parasitaemia $<0.01 \%$. Blood and faecal culture were negative, as were dengue serology and NS1 antigen detection. He met none of the clinical or biological WHO criteria for severe $P$. falciparum malaria and was admitted to hospital for supervision of oral treatment with DP [40 mg dihydroartemisinin (DHA) plus $320 \mathrm{mg}$ piperaquine tetraphosphate (PPQ); Eurartesim $\odot$; Sigma-Tau laboratory] at the maximal dosage of four pills once daily between meals for 3 days, recommended by the Sigma-Tau laboratory in absence of data on which to base a dose recommendation in patients weighing above $100 \mathrm{~kg}$. He was discharged at the third day with no more fever and a negative QBC test. He took the correct doxycycline prophylaxis and used a bed-net. He was asymptomatic at day 12 with a negative QBC test. At day 20, he complained of fever $\left(38.9^{\circ} \mathrm{C}\right)$ and diarrhoea. Laboratory examination revealed recurrence of $P$. falciparum with $0.5 \%$ parasitaemia and the absence of co-infection. A thin blood smear found late-stage trophozoites without gametocytes. He was successfully cured by the standard oral therapeutic course of a fixed atovaquone-proguanil combination [atovaquone $(250 \mathrm{mg})$ plus proguanil hydrochloride $(100 \mathrm{mg})$, Malarone $\left.{ }^{\circledR}\right]$, four pills during meals once daily for 3 days. Clinical and parasitological follow-up were completed at day 22, 27, and 48 without recurrence.

Though ACT failure is infrequent in Africa, the genome of the recurrent $P$. falciparum isolate was sequenced and searched for polymorphisms involved in antimalarial drug resistance. The $k 13$ gene was amplified by polymerase chain reaction (PCR) with the nested PCR method previously described [13]. The following primers were used for PCR: 3' GGG AAT CTG GTG GTA ACA GC 5' and 3' CGG AGT GAC CAA ATC TGG GA 5'; 3' GCC TTG TTG AAA GAA GCA GA $5^{\prime}$ and $3^{\prime}$ GCC AAG CTG CCA TTC ATT TG 5'. The K13 propeller gene was successfully sequenced, and the result was compared to the reference 3D7 strain. No mutation was identified in the propeller domain of the $k 13$ gene. Two fragments of the $p f m d r 1$ gene ( $P$. falciparum multidrug resistance 1) were also amplified according to the description by Wurtz et al., revealing N86, 184F, S1034 and N1042 alleles [16]. The pfcrt gene ( $P$. falciparum chloroquine resistance transporter) was also sequenced, as previously described [17], and the 72-76 haplotype found was CVIET. Finally, the copy number of the two genes $p f m d t$ and $p f t e t Q$, which in vitro reduced susceptibility to doxycycline in Africa, was determined by finding one copy of pfmdt and two copies of pftetQ [18-20].

\section{Discussion}

Artemisinin derivatives clear parasitaemia more rapidly than all other currently available anti-malarial agents, including atovaquone-proguanil [21]. In 2010, DP was recommended by WHO [22] for the treatment of uncomplicated $P$. falciparum malaria, providing a promising alternative to other artemisinin-based combinations on the basis of its high efficacy, excellent safety profile, oncedaily dosing scheme, and prolonged post-treatment prophylactic protection [23]. In the French army, DP is the available first-line treatment.

In this case, $P$. falciparum reinfection cannot be excluded because of the lack of comparative genome 
sequencing between the two isolates. However, the low $P$. falciparum transmission in Djibouti [24-26] and the 19-day delay both indicated that malaria relapse had occurred; this was further supported by the fact that this occurred despite prophylaxis, and only late trophozoite forms of the parasites without gametocytes appeared on the thin blood smear.

DP was well tolerated, and the whole course of treatment was well completed. Failure more likely resulted from inadequate dosage, because there are no data on which to base a dose recommendation in patients weighing above $100 \mathrm{~kg}$ according to the European Medicines Agency (EMA) [27]. In the absence of toxicity data in patients weighing above $100 \mathrm{~kg}$, the DP maximal dosage (i.e., $1280 \mathrm{mg} /$ day PPQ and $160 \mathrm{mg} /$ day DHA indicated for body weight 75 to $100 \mathrm{~kg}$ ) was administered. This corresponded to a cumulative dose of $4.6 \mathrm{mg} / \mathrm{kg}$ DHA and $37 \mathrm{mg} / \mathrm{kg}$ PPQ in the present patient, which is far below the WHO recommended ranges $(6-20 \mathrm{mg} /$ $\mathrm{kg}$ DHA and $48-78 \mathrm{mg} / \mathrm{kg} \mathrm{PPQ}$ ) [22]. Indeed, WHO recommended the use of a PPQ dose of $1600 \mathrm{mg} /$ day for body weigh above $80 \mathrm{~kg}$ [22]. In the literature, concerns have been raised over potential DP under-dosing in young children [28], and the 2013 Worldwide Antimalarial Resistance Network (WWARN) has explored the relationship between weight-adjusted DP dosage $(\mathrm{mg} / \mathrm{kg})$ and therapeutic efficacy in a meta-analysis [23]. Data of 7072 patients from prospective studies investigating DP efficiency were pooled. Those without molecular evidence for failure or with follow-up less than 28 days were excluded. The primary endpoint was the PCRadjusted risk of $P$. falciparum recrudescence at the end of the study follow-up. Secondary endpoints included new $P$. falciparum infections, parasitological clearance rates, and gametocyte carriage. No patient was heavier than $100 \mathrm{~kg}$. Twenty-eight patients weighed from 75 to $100 \mathrm{~kg}$, and the median cumulative dose in this group was $37.4 \mathrm{mg} / \mathrm{kg}$ (32.8-48.3) for PPQ and $4.7 \mathrm{mg} / \mathrm{kg}$ (4.16.4) for DHA; these were close to the rates in the present patient and corresponded to $71.4 \%(20 / 28)$ of patients below the WHO recommended dose [22]. The WWARN DP Study Group clearly showed that a total PPQ dose below $40 \mathrm{mg} / \mathrm{kg}$ predicted risk of recrudescence failure [23]. Additionally, in this previous study, six factors were reported to be associated with the risk of malaria recrudescence with PPQ [23]. In the present case, two of these six factors were found: the PPQ total dose and the body weight.

Thus, there is much evidence that DP treatment outcome depends on the PPQ plasma concentration. In DP, the artemisinin derivative DHA is responsible for a rapid initial reduction in parasitemia by targeting the parasitized erythrocytes, while PPQ is the partner drug that has a much longer elimination half-life to complete long-term parasite clearance [29]. Moreover, PPQ is of a lipophilic nature with a large volume of distribution [27]. For all of these reasons, it can assume that DP treatment failure in the present case was more related to PPQ under-dosing.

Interestingly, similar overweight-related failures have been documented with atovaquone-proguanil [30, 31]. In a series of 347 P. falciparum-infected travellers, atovaquone-proguanil therapeutic failures were overrepresented among patients weighing more than $100 \mathrm{~kg}$ [3/12 in the group (100-115 kg) receiving a standard atovaquone-proguanil regimen versus $2 / 335$ in patients $<100 \mathrm{~kg}$ ] [32]. These data emphasize the lack of an alternative validated malaria treatment in overweight patients.

However, clinical failure by resistance cannot be excluded. Multidrug resistance to DP is currently emerging in Cambodia, where recrudescent infections have increased from $15.4 \%$ in $2011-2013$ to $39 \%$ in $2012-2014 ; 84 \%$ of treated patients presented with parasite clearance half-lives longer than $5 \mathrm{~h}$ in 2012 2104 , and $57 \%$ were still parasitaemic at $72 \mathrm{~h}[33,34]$. All the C580Y k13 mutant parasites collected from recrudescent patients after a 3-day DP treatment were resistant in vitro by PPQ survival assay [35]. DHA resistance is a real threat in African countries [4]. However, no mutation in the $k 13$ gene was found in the present patient's isolate. However, clinical failure by resistance cannot be excluded even if no mutations were identified in $k 13$. Artemisinin failures seem not to be associated with $k 13$ polymorphisms in Africa [15, 36]. However, in the absence of in vitro phenotyping (ring-stage survival assay) as well as data on parasite clearance rate, there was no evidence of resistance to artemisinin.

Decreased susceptibility or parasite resistance to artemisinin partner drugs has been observed in Africa, where single nucleotide polymorphisms in pfcrt and pfmdr1 have been identified in recurrent infections with ACT partners like lumefantrine, mefloquine or amodiaquine [37-41]. However, there is no data currently supporting the involvement of the pfcrt or $p f m d r 1$ genes in PPQ or DHA resistance $[17,42]$. The isolate contained two copies of the pftet $Q$ gene, suggesting that the parasites were resistant to doxycycline [18-20]. This result may explain why, even as he took doxycycline as prophylaxis after his treatment by dihydroartemisinin-piperaquine, the patient had recurrent malaria.

\section{Conclusion}

Sub-optimal dosing of either component of ACT can result in incomplete elimination of the parasite biomass 
and subsequent recrudescence, both of which are important driving forces for the selection of parasites with reduced drug susceptibility. ACT regimens should absolutely be deployed using optimal dosing strategies to maximize the likelihood of rapid clinical and parasitological cure, minimize transmission, and retard the onset and spread of resistances. Overweight patients are at particular risk of under-dosing. In some military units, the soldiers often weigh more than 90-100 kg. Should physicians automatically exclude the use of dihydroartemisinin-piperaquine as an anti-malarial treatment in these patients in the absence of data in patients weighing above $100 \mathrm{~kg}$ ? Until studies assessing how to adapt treatment are performed (increase the duration or the daily dose or repeat a course later), patients weighing more than $100 \mathrm{~kg}$ should be aware of the higher risk of therapeutic failure and should be closely monitored at least until day 28 , and beyond if possible. This therapeutic failure with DP by under-dosing highlighted the importance of appropriate dosing guidelines and the need of research data (efficacy, pharmacokinetics and pharmacodynamics) in over-weight patient group.

\section{Abbreviations}

ACT: artemisinin-based combination therapy; DHA: dihydroartemisinin; DP: dihydroartemisinin-piperaquine; PCR: polymerase chain reaction; Pfcrt: Plasmodium falciparum chloroquine resistance transporter; Pfmdt: Plasmodium falciparum metabolite drug transporter; Pfmdr1: Plasmodium falciparum multidrug resistance; PPQ: piperaquine; QBC: quantitative buffy coat; RDT: rapid diagnostic test; WWARN: Worldwide Antimalarial Resistance Network; WHO: World Health Organization.
\end{abstract}

\section{Authors' contributions}

JBR, SV and NP carried out the diagnostic tests, monitored the patient, collected clinical and epidemiological data. BP and MM carried out the molecular genetic study. JBR, BP, SV, FS and EJ wrote the first manuscript. All authors have read and approved the final manuscript.

\section{Author details}

1 Service de Pneumologie, Hôpital d'Instruction des Armées Laveran, Marseille, France. ${ }^{2}$ Groupe Médico-chirurgical Bouffard, Djibouti, Republic of Djibouti.

${ }^{3}$ Unité de Parasitologie et d'Entomologie, Département des Maladies Infectieuses, Institut de Recherche Biomédicale des Armées, Marseille, France. ${ }^{4}$ Unité de Recherche sur les Maladies Infectieuses et Tropicales Emergentes, UM 63, CNRS 7278, IRD 198, Inserm 1095, Aix Marseille Université, Marseille, France. ${ }^{5}$ Centre National de Référence du Paludisme, Marseille, France. ${ }^{6}$ Service de Pneumologie, Hôpital d'Instruction des Armées Clermont-Tonnerre, Brest, France. ${ }^{7}$ Equipe Résidente de Recherche en Infectiologie Tropicale, Institut de Recherche Biomédicale des Armées, Hôpital d'Instruction des Armées, Marseille, France. ${ }^{8}$ Service de pathologie infectieuse et tropicale, Hôpital d'Instruction des Armées Laveran, Marseille, France. ${ }^{9}$ Ecole du Val de Grâce, Paris, France.

\section{Acknowledgements}

The authors thank Nicolas Benoit from the Equipe Résidente de Recherche en Infectiologie Tropicale, Institut de Recherche Biomédical des Armées for his technical support.

\section{Competing interests}

The authors have declared that they have no competing interests.

\section{Ethics approval and consent to participate}

According to the French legislation, bio-banking and secondary use for scientific purposes of human clinical samples used for malaria diagnostics are possible as long as the corresponding patients are informed and have not indicated any objections. This requirement was fulfilled here because oral information was given to the patient, and no immediate or delayed patient opposition was reported by the hospital clinicians. Moreover, samples received at the French Malaria Reference Center were registered and declared for research purposes as a bio-bank for the French National Institute of Health Survey. No institutional review board approval is required according to French legislation (article L. 1111-7 du Code de la Santé Publique, article L. 1211-2 du Code de Santé Publique, articles 39 et suivants de la loi 78-17 du 6 janvier 1978 modifiée en 2004 relative à l'informatique, aux fichiers, et aux libertés).

\section{Funding}

This study was supported by the Institut national de veille sanitaire (grant CNR Paludisme).

Received: 7 July 2016 Accepted: 13 September 2016

Published online: 20 September 2016

\section{References}

1. Bhattarai A, Ali AS, Kachur SP, Mårtensson A, Abbas AK, Khatib R, et al. Impact of artemisinin-based combination therapy and insecticidetreated nets on malaria burden in Zanzibar. PLoS Med. 2007:4:309.

2. WHO. World malaria report 2015. Geneva, World Health Organization. http://apps.who.int/iris/bitstream/10665/200018/1/9789241565158_eng. pdf.

3. Dondorp AM, Nosten F, Yi P, Das D, Phyo AP, Tarning J, et al. Artemisinin resistance in Plasmodium falciparum malaria. N Engl J Med. 2009:361:455-67.

4. Ashley EA, Dhorda M, Fairhurst RM, Amaratunga C, Lim P, Suon S, et al. Spread of artemisinin resistance in Plasmodium falciparum malaria. N Engl J Med. 2014;371:411-23.

5. Witkowski B, Amaratunga C, Khim N, Sreng S, Chim P, Kim S, et al. Novel phenotypic assays for the detection of artemisinin-resistant Plasmodium falciparum malaria in Cambodia: in vitro and ex vivo drug-response studies. Lancet Infect Dis. 2013;13:1043-9.

6. Ariey F, Witkowski B, Amaratunga C, Beghain J, Langlois A-C, Khim N, et al. A molecular marker of artemisinin-resistant Plasmodium falciparum malaria. Nature. 2014;505:50-5.

7. Amaratunga C, Witkowski B, Khim N, Menard D, Fairhurst RM. Artemisinin resistance in Plasmodium falciparum. Lancet Infect Dis. 2014;14:449-50.

8. Takala-Harrison S, Jacob CG, Arze C, Cummings MP, Silva JC, Dondorp AM, et al. Independent emergence of artemisinin resistance mutations among Plasmodium falciparum in Southeast Asia. J Infect Dis. 2015;211:670-9.

9. Fairhurst RM. Understanding artemisinin-resistant malaria: what a difference a year makes. Curr Opin Infect Dis. 2015;28:417-25.

10. Kamau E, Campino S, Amenga-Etego L, Drury E, Ishengoma D, Johnson $\mathrm{K}$, et al. K13-propeller polymorphisms in Plasmodium falciparum parasites from sub-Saharan Africa. J Infect Dis. 2015;211:1352-5.

11. Taylor SM, Parobek CM, DeConti DK, Kayentao K, Coulibaly SO, Greenwood BM, et al. Absence of putative artemisinin resistance mutations among Plasmodium falciparum in sub-Saharan Africa: a molecular epidemiologic study. J Infect Dis. 2015;211:680-8.

12. Torrentino-Madamet $M$, Collet L, Lepère JF, Benoit N, Amalvict R, Ménard D, et al. K13-propeller polymorphisms in Plasmodium falciparum isolates from patients in Mayotte in 2013 and 2014. Antimicrob Agents Chemother. 2015;59:7878-81.

13. Torrentino-Madamet M, Fall B, Benoit N, Camara C, Amalvict R, Fall M, et al. Limited polymorphisms in $\mathrm{k} 13$ gene in Plasmodium falciparum isolates from Dakar, Senegal in 2012-2013. Malar J. 2014;13:472.

14. Boussaroque A, Fall B, Madamet M, Camara C, Benoit N, Fall M, et al. Emergence of mutations in the $\mathrm{K} 13$ propeller gene of Plasmodium falciparum isolates from Dakar, Senegal, in 2013-2014. Antimicrob Agents Chemother. 2016;60:624-7. 
15. Ménard D, Khim N, Beghain J, Adegnika AA, Kremsner PG, Ramherter M, et al. A worldwide map of Plasmodium falciparum artemisinin resistance. N Engl J Med. 2016;74:2453-64.

16. Wurtz N, Fall B, Pascual A, Fall M, Baret E, Camara C, et al. Role of Pfmdr1 in in vitro Plasmodium falciparum susceptibility to chloroquine, quinine, monodesethylamodiaquine, mefloquine, lumefantrine, and dihydroartemisinin. Antimicrob Agents Chemother. 2014;58:7032-40.

17. Briolant S, Henry M, Oeuvray C, Amalvict R, Baret E, Didillon E, et al. Absence of association between piperaquine in vitro responses and polymorphisms in the pfcrt, pfmdr1, pfmrp, and pfnhe genes in Plasmodium falciparum. Antimicrob Agents Chemother. 2010:54:3537-44.

18. Briolant S, Wurtz N, Zettor A, Rogier C, Pradines B. Susceptibility of Plasmodium falciparum isolates to doxycycline is associated with pftetQ sequence polymorphisms and pftetQ and pfmdt copy numbers. J Infect Dis. 2010;201:153-9.

19. Madamet M, Gaillard T, Velut G, Ficko C, Houzé P, Bylicki C, et al. Malaria prophylaxis failure with doxycycline, Central African Republic, 2014. Emerg Infect Dis. 2015;8:1485-6.

20. Gaillard T, Briolant S, Houzé S, Baragatti M, Wurtz N, Hubert V, et al. PftetQ and pfmdt copy numbers as predictive molecular markers of decreased ex vivo doxycycline susceptibility in imported Plasmodium falciparum malaria. Malar J. 2013;12:414

21. Nosten F, White NJ. Artemisinin-based combination treatment of falciparum malaria. Am J Trop Med Hyg. 2007;77(6 Suppl):191-2.

22. WHO. Guidelines for the treatment of malaria. Geneva, World Health Organization. http://apps.who.int/iris/bitstr eam/10665/162441/1/9789241549127_eng.pdf?ua=1\&ua=1.

23. WorldWide Antimalarial Resistance Network (WWARN), DP Study Group The effect of dosing regimens on the antimalarial efficacy of dihydroartemisinin-piperaquine: a pooled analysis of individual patient data. PLoS Med. 2013;10:1001564.

24. Khaireh BA, Briolant S, Pascual A, Mokrane M, Machault $V$, Travaillé C, et al. Plasmodium vivax and Plasmodium falciparum infections in the Republic of Djibouti: evaluation of their prevalence and potential determinants. Malar J. 2012;11:395.

25. Khaireh BA, Assefa A, Guessod HH, Basco LK, Khairh MA, Pascual A, et al. Population genetics analysis during the elimination process of Plasmodium falciparum in Djibouti. Malar J. 2013;12:201.

26. Faulde MK, Rueda LM, Khaireh BA. First record of the Asian malaria vector Anopheles stephensi and its possible role in the resurgence of malaria in Djibouti, Horn of Africa. Acta Trop. 2014;139:39-43.

27. Eurartesim, INN-piperaquine \& INN dihydroartemisinin-WC500118113. pdf. http://www.ema.europa.eu/docs/en_GB/document_library/EPAR_Product_Information/human/001199/WC500118113.pdf.

28. Zongo I, Somé FA, Somda SAM, Parikh S, Rouamba N, Rosenthal PJ, et al. Efficacy and day 7 plasma piperaquine concentrations in African children treated for uncomplicated malaria with dihydroartemisinin-piperaquine. PLOS ONE. 2014;9:103200.

29. Price RN, Hasugian AR, Ratcliff A, Siswantoro H, Purba HLE, Kenangalem $E$, et al. Clinical and pharmacological determinants of the therapeutic response to dihydroartemisinin-piperaquine for drug-resistant malaria. Antimicrob Agents Chemother. 2007;51:4090-7.
30. Cordel H, Cailhol J, Matheron S, Bloch M, Godineau N, Consigny P-H, et al. Atovaquone-proguanil in the treatment of imported uncomplicated Plasmodium falciparum malaria: a prospective observational study of 553 cases. Malar J. 2013;12:399.

31. Durand R, Prendki V, Cailhol J, Hubert V, Ralaimazava P, Massias L, et al. Plasmodium falciparum malaria and atovaquone-proguanil treatment failure. Emerg Infect Dis. 2008:14:320-2.

32. Musset L, Bouchaud O, Matheron S, Massias L, Le Bras J. Clinical atovaquone-proguanil resistance of Plasmodium falciparum associated with cytochrome b codon 268 mutations. Microbes Infect. 2006:8:2599-604

33. Leang R, Taylor WRJ, Bouth DM, Song L, Tarning J, Char MC, et al. Evidence of Plasmodium falciparum malaria multidrug resistance to artemisinin and piperaquine in Western Cambodia: dihydroartemisinin-piperaquine open-label multicenter clinical assessment. Antimicrob Agents Chemother. 2015:59:4719-26.

34. Spring MD, Lin JT, Manning JE, Vanachayangkul P, Somethy S, Bun R, et al. Dihydroartemisinin-piperaquine failure associated with a triple mutant including kelch13 C580Y in Cambodia: an observational cohort study. Lancet Infect Dis. 2015;15:683-91.

35. Duru V, Khim N, Leang R, Kim S, Domergue A, Kloeung N, et al. Plasmodium falciparum dihydroartemisinin-piperaquine failures in Cambodia are associated with mutant K13 parasites presenting high survival rates in novel piperaquine in vitro assay: retrospective and prospective investigations. BMC Med. 2015;13:305.

36. Conrad MD, Bigira V, Kapisi J, Muhindo M, Kamya MR, Havlir DV, et al. Polymorphisms in $\mathrm{K} 13$ and falcipain-2 associated with artemisinin resistance are not prevalent in Plasmodium falciparum isolated from Ugandan children. PLOS ONE. 2014;9:105690.

37. Mwai L, Kiara SM, Abdirahman A, Pole L, Rippert A, Diriye A, et al. In vitro activities of piperaquine, lumefantrine, and dihydroartemisinin in Kenyan Plasmodium falciparum isolates and polymorphisms in pfcrt and pfmdr 1 . Antimicrob Agents Chemother. 2009;53:5069-73.

38. Duraisingh MT, Roper C, Walliker D, Warhurst DC. Increased sensitivity to the antimalarials mefloquine and artemisinin is conferred by mutations in the pfmdrl gene of Plasmodium falciparum. Mol Microbiol. 2000;36:955-61.

39. Dahlström S, Aubouy A, Maïga-Ascofaré O, Faucher J-F, Wakpo A, Ezinmègnon $\mathrm{S}$, et al. Plasmodium falciparum polymorphisms associated with ex vivo drug susceptibility and clinical effectiveness of artemisininbased combination therapies in Benin. Antimicrob Agents Chemother. 2014;58:1-10.

40. Sisowath C, Stromberg J, Martensson A, Msellem M, Obondo C, Björkman A, et al. In vivo selection of Plasmodium falciparum.pfmdr1 86 $\mathrm{N}$ coding alleles by artemether-lumefantrine (Coartem). J Infect Dis. 2005;191:1014-7.

41. Dokomajilar C, Nsobya SL, Greenhouse B, Rosenthal PJ, Dorsey G. Selection of Plasmodium falciparum pfmdr 1 alleles following therapy with artemether-lumefantrine in an area of Uganda where malaria is highly endemic. Antimicrob Agents Chemother. 2006;50:1893-5.

42. Pascual A, Madamet M, Bertaux L, Amalvict R, Benoit N, Travers D, et al. In vitro piperaquine susceptibility is not associated with the Plasmodium falciparum chloroquine resistance transporter gene. Malar J. 2013;12:431.

\section{Submit your next manuscript to BioMed Central and we will help you at every step:}

- We accept pre-submission inquiries

- Our selector tool helps you to find the most relevant journal

- We provide round the clock customer support

- Convenient online submission

- Thorough peer review

- Inclusion in PubMed and all major indexing services

- Maximum visibility for your research

Submit your manuscript at www.biomedcentral.com/submit

Ciomed Central 